\title{
Funiculite em um bovino após castração
}

Marquiliano Farias de Moura", Ruy Brayner de Oliveira Filho, Igor Mariz Dantas, Walter Henrique Cruz Pequeno, Karla Campos

Malta, José Bezerra Filho, Valber Onofre Araújo, Suedney de Lima Silva

Hospital Veterinário, Centro de Ciências Agrárias, Universidade Federal da Paraíba (UFPB), Areia, PB, Brasil

*Autor correspondente

e-mail: marquiliano@hotmail.com

\section{Resumo}

A castração de animais do sexo masculino é uma das técnicas de manejo reprodutivo mais utilizadas na produção de animais domésticos. Vários métodos possibilitam a castração, sendo os mais utilizados a remoção cirúrgica, dano irreversível na gônada e atrofia por estenose dos vasos. A castração por estenose dos vasos, utilizando burdizzo, é uma das técnicas mais comuns na castração de bovinos, pois dispensa abertura da bolsa escrotal e reduz os cuidados pós-operatórios. No entanto, esse método pode causar complicações, principalmente quando a compressão dos vasos é realizada no local inadequado (muito próximo aos testículos) ou o tempo de compressão é insuficiente para promover adequada hemostasia. 0 presente trabalho relata um caso de funiculite em bovino atendido no Hospital Veterinário da Universidade Federal da Paraíba, com cinco anos de idade, com histórico de castração por estenose dos vasos testiculares (com uso do burdizzo) havia aproximadamente dois meses. Dois dias antes do atendimento, o proprietário observou o animal claudicando, sem ingerir alimentos e com aumento de volume no escroto. Ao exame físico, o animal apresentava bolsa escrotal com aumento de volume, temperatura elevada e consistência endurecida; o testículo esquerdo estava sem mobilidade e rígido à palpação; o testículo direto estava flácido. Além disso, foi observado que a claudicação era consequência da elevada sensibilidade dolorosa na bolsa escrotal. Optou-se pelo tratamento cirúrgico com orquiectomia e ablação total da bolsa escrotal devido à intensa fibrose das estruturas. Antes da realização do procedimento cirúrgico o animal recebeu anti-inflamatório $(0,1 \mathrm{mg} / \mathrm{kg}$ de dexametasona) por sete dias para melhora dos sinais clínicos e do desconforto apresentado. Após o procedimento, deu-se continuidade a terapia anti-inflamatória por três dias ( $3 \mathrm{mg} / \mathrm{kg}$ cetoprofeno), instituiu-se terapia antimicrobiana com 20 $\mathrm{mg} / \mathrm{kg}$ de oxitetraciclina a cada 48 horas, em um total de 4 aplicações, e passou-se a realizar o tratamento da ferida operatória duas vezes por dia. 0 protocolo instituído permitiu plena recuperação do animal. No exame patológico, os testículos apresentavam atrofia em curso. Nas túnicas vaginais havia acentuada fibrose; 
os epidídimos apresentavam necrose. 0 presente relato mostra a importância do conhecimento anatômico do aparelho reprodutor masculino, bem como dos procedimentos corretos a serem adotados durante esta técnica de castração incruenta, principalmente no que diz respeito ao local correto de emasculação e tempo de permanência do emasculador, por parte do operador. Como este procedimento muitas vezes não é realizado por um médico veterinário, faz-se necessário o treinamento adequado das pessoas que irão realizá-lo, para evitar os prejuízos econômicos devido à diminuição no ganho de peso, gasto com medicamentos e honorários veterinários, bem como para minimizar o sofrimento dos animais. Os procedimentos acima mencionados se mostraram eficientes para o caso em questão, podendo ser utilizados para o tratamento de outros animais com casos semelhantes. 